\title{
Design of educational artifacts as support to learning process
}

\author{
Adson Eduardo Resende ${ }^{\mathrm{a}}$ and Flávio Henrique Vasconcelos ${ }^{\mathrm{b}}$ \\ ${ }^{a}$ Laboratory of Ergonomics and Technical High School, ${ }^{b}$ Department of Electrical Engineering, Federal \\ University of Minas Gerais, Av. Antônio Carlos, 6627 Campus Pampulha Cep. 31270-901 Belo Horizonte/MG, \\ Brasil. Fone: 553134097525
}

\begin{abstract}
The aim of this paper is to identify utilization schemes developed by students and teachers in their interaction with educational workstations in the electronic measurement and instrumentation laboratory at the Department of Electrical Engineering in the Federal University of Minas Gerais (UFMG), Brazil. After that, these schemes were used to design a new workstation. For this, it was important to bear in mind that the mentioned artifacts contain two key characteristics: (1) one from the designers themselves, resulting from their experience and their technical knowledge of what they are designing and (2) the experience from users and the means through which they take advantage of and develop these artifacts, in turn rendering them appropriate to perform the proposed task - the utilization schemes developed in the process of mediation between the user and the artifact. The satisfactory fusion of these two points makes these artifacts a functional unit - the instruments. This research aims to demonstrate that identifying the utilization schemes by taking advantage of user experience and incorporating this within the design, facilitates its appropriation and, consequently, its efficiency as an instrument of learning.
\end{abstract}

Keywords: ergonomic design, artifact, instrument, learning process

\section{1- Introduction}

Artifact design demands that the designer solve conflicts which arise from the many partial logics from the various users of a similar artifact. Understanding the relations established among the many subsystems that make up the work activity and its environment inevitably leads to the need to develop design methods capable of dealing with the inherent demands of this complexity. In this light, it is possible to infer that the existence of an interface between the work artifact and the user must be considered when drafting a design. It is the very exercise of the use of this interface which allows users to construct their own experiences. Consequently, the design requirements are found within experience itself, and, to recover this and impel the emergence of design needs, one must forgo the methods which are linked to the current conditions of the accepted practices of design. The evolution from artifact to instrument results from the association of artifacts with the utilization schemes presented by users, a reflection of their own 1

${ }^{*}$ Corresponding author. e-mail adson@ufmg.br experiences. Methodologies, such as the Ergonomic Analysis of Work, supported and guided by use activity, can aid in the construction of a conscientious reflection on both complexity and variables which arise while using a work environment. Observations from the present study identified a void between the design of the workbench and the real work performed by the teachers and students, and their utilization schemes. Design should reflect a conception process which incorporates the characteristics of both user activities and user experience.

\section{2- Artifacts and their dynamics of use}

Understanding how the interaction between man and artifact can be presented from a wide range of viewpoints, in turn expanding one's understanding of the user's condition in the process.

According to Folcher and Rabardel [12], in the interactions of men with machines and technical devices, be they material or symbolic, three types of approaches can be pointed out. The first focuses on "those centered around the interaction between man and machine" Folcher and Rabardel [12], a relation 
mediated by an interface that attempts to provide man with a better comprehension of the specific equipment's possible actions and/or the use of space. The second refers to those "who consider man and machine as a system engaged in a task", considering that, in this approach, one or more men and machines van be found in a combined form, with which one attempts to achieve a predetermined goal. In the third, in an approach centered around the mediation of activity through the use of artifacts, these relations are represented by cultural and productive instruments and act in the transformation of this subject's relations with the world, as well as in the transformation of one's activities and tasks [12]. This mediated action is where the use of human instruments is intimately linked to the process of transformation and development of context, maintaining human relationships, which are mediated by artifacts, in a constant process of change, adapting themselves to the variables that arise and shape its development.

The mediated activity approach finds its origins in the work of Lev Vygotsky [21], who studied the human development mediated by artifacts/instruments. From this point of view, in the process of interaction, man is seen as a "socially situated subject, bearer of meaning and inheritor of a culture which he contributed to renewing. $\mathrm{He}$ is intentionally engaged in activities that are, for him, finished and meaningful", Folcher and Rabardel [12]. In this approach, the unit of analysis, according to the authors, becomes more complex and hinges on two main principles: on the one hand, the performance of tasks (productive activity), and on the other hand, constructive activity, that is, the creation of internal and external resources (instruments, competencies, schemes and conceptualizations, and value systems), in which the subject produces the conditions and means for future activity [12].

The analysis criteria are strongly linked to the process of the adaptation of the artifacts to the activity for which they were designed. The theoretical picture which is outlined by this approach centers around the Theory of Activity and is clearly linked to the development of works from Vygotsky [21], as well as from Alexis Léontiev [14] and Yrjö Engeströn [11]. This group of authors from Eastern Europe firmly analyzed the concepts of mediated activity and their works supported the development of the concept of activity mediated by instruments, especially that geared toward the field of education.

\subsection{Artifact-from the process to the instrument}

Here, it is necessary to consolidate the distinction between artifact and instrument. To reach this point, it was important to construct a prior concept, focused on mediated activity, in which the users are in constant interaction with the artifact. In this sense, this text aims to delve into the concepts of artifact and instrument, moving toward the understanding of the genesis of the production of instruments and their dimensions within an activity.

As mentioned above, an artifact can be either material or symbolic; it can be conceived by specialists or developed within a course activity by the users themselves. The "instrument", according to Rabardel [16], cannot be merely reduced to the artifact; considering it as such would mean admitting that this reduction is in fact possible. An instrument is a functional unit, with a minimum significance, and is the result of a process of mediation in which various heterogeneous components are associated. For example: "when using a wrench rather than a hammer, the subject depends on specific properties of the artifact (wrench): length, mass, hardness of the part used to hammer. It is the previously established utilization scheme that allows one to recognize the presence of these characteristics in the wrench and attribute to it the meaning of the hammer artifact, as well as locally regulate the characteristics of the action as regards the specific properties of the wrench", Rabardel e Folcher [12].

In this manner, the result of this association allows for a transformation of this artifact, appropriated and changed in meaning by the user and adapted to its activity. This idea of the instrument of a "mixed unit", according to Rabardel [17], presents two main components:

- The artifact: material or symbolic, produced by the subjects or other (designers, for example);

- Utilization schemes: result from the subject's own, autonomous construction or from the appropriation of the social utilization schemes developed previously, not necessarily including the participation of the subject of the activity.

Frequently, however, "this process cannot be put into practice or, when it is, it leads to problematic situations", Rabardel and Folcher [12]. These problematic situations in which the artifacts are not 
made into instruments can, eventually, hinder the users from performing their activities. This is due to the fact that the artifacts are designed to carry out previously defined functions. Instrumentalization is always conducted in an attempt to render the artifact appropriate for the user and for the use situation for which it was conceived. These authors also highlight another aspect of these utilization schemes, that of the "collective use", which is due to the fact that the user is not isolated in the use of these artifacts; a group can share, even at the same time, a certain artifact or group of artifacts, rendering them an element of the coordination of individual action in obtaining results that are in common within a given community.

\section{2 - The design}

Based on the concept that distinguishes artifact and instrument, the new artifact design must be conducted in such a way as to accommodate the utilization schemes. This accommodation can be achieved by providing the users with a "creative maneuvering area", Daniellou [6]. Within this maneuvering area, flexible spaces allow the users to use their experience by interacting with the artifacts, aimed at instrumentalization, providing a sequence to the design, modifying and developing their attributes, and adapting them to the true needs of the task. To provide this maneuvering area is to give the user the recognition that he is decisive in the instruments' conception process. One of the consequences of providing this maneuvering area to the user is the reduction in the very accommodation period of the artifacts, that is, it reduces the time necessary for them to achieve their condition of instrument - as a functional unit. In summary, the aim is to achieve a greater efficiency of the designed artifacts, in turn diminishing the estrangement provoked in the users when their old work instruments are substituted by new artifacts.

Another factor that differentiates the designing of this workbench is to based on work from Yves Clot [5], who differentiates four passages which lead to the consolidation of the mediated experience, creating what is called "collective memory", to which each individual resorts in order to be able to interact with others, facing the situations to which they are exposed. Clot affirms that, when beginning a new occupation/learning, we bring our own experience with ourselves - the "personal". Next, we attempt to familiarize ourselves with the rules, norms, or statutes of the task that we must resolve the "impersonal". Soon, we begin to perceive that, by following only our own personal experience and the rules, we are unable to perform the activity that was required of us. At this point, we begin to observe how others are acting and thus learn with them - thus arriving at the "interpersonal". It is the passage form the impersonal to the interpersonal that a leap in quality is established. After this, the interaction among individuals is intensified and we reach the final stage, which is the "transpersonal", in which the experiences are mixed, forming the collective memory, which is shortly thereafter appropriated by each individual and begins to be constituted as one's own personal experience.

It is important to highlight this construction, emphasizing that it is one of the main elements responsible for the creation of utilization strategies, in turn defining certain "styles" as work from a specific group of individuals. In the case of a designed workbench, this characteristic of the construction process of this collective experience was particularly explored, given that the workbench from laboratories finds its main focus in learning, which is essentially interactive and a social construction.

\section{3- Methodology}

The data survey process made use of the ergonomic work analysis (EWA), which has already been formalized in both its general and operational aspects, see Guérin [13], Lima [15]. Its main principle consists of providing evidence of the "true activity", as compared to the formal organization, Daniellou [7], which presupposes the exposure of informal knowledge, the implicit knowledge of the actors in a given situation, the criteria which guide their actions, and the conflicting objectives that shape their behaviors during the execution of any single activity. Such knowledge is commonly only accessible after long periods of observations and common experience alongside the users, who are exposed to natural situations, that is, inserted in the context where they perform their daily activities. Both the objective condition as well as the subjective condition can be found in these situations, in other words, the means and material and organizational instruments to carry out the tasks and the forms of these are, in fact, performed by the individuals. Thus, on the one hand, we have variability (technical, organizational, and human) of 
the situation, while on the other hand we have the explanation of how the users react to the difficulties and attempt to overcome these throughout the course of their activities.

The process of systematic analysis of these activities, in general, is constructed as of the verbal expression shown by the actors concerning their activity and the components that affect and/or potentialize their accomplishment. These verbalizations can be spontaneous, but are generally "provoked" while performing an activity (uninterrupted verbalizations) or after their accomplishment (consecutive verbalizations), in an attempt to reveal the reasons, means, and aims of the performed actions. Observing one's behavior in a given situation is followed by the self-confrontation of the data raised by the actors themselves, aimed at the clarification of the aspects of the identified utilization strategies and schemes that have not been understood, as well as the validation of these observations $[4,15,19,20,22]$. The ergonomics of conception has developed some particular instruments, as it works, to a certain extent, with the future action and not exactly with that in progress. The next item will describe some of these instruments.

\subsection{Ergonomics of conception}

It is important to clarify some points regarding designs, such as the fact that they express themselves in two different forms: the design of new artifacts and the re-design of existing artifacts. In addition, these two finalities require distinct processes of conception. According to Daniellou [10], for existing artifacts in use, a detailed analysis of the existing artifact must be performed. For the design of new artifacts, the analysis must be geared toward the "situations of reference aimed at predicting certain dimensions of future situations so as to guide the designers' explorations" [10], as well as for the situations of characteristic action (SCA's), "which are a group of determining factors whose simultaneous presence will condition the structure of the activity" [10]. In the same work, Daniellou defines the SCA's as "units of task analysis transferable to the future situations".

With this, the designer has no definition of what will be the future activity involving the design, but rather the construction of possible scenarios. The most common in the ergonomics of conception is the redesign of already existing artifacts, in which the praxis indicates a method of conception which stems from the analysis phase of the activity for experimentation. It is not difficult to understand why this occurs: "the activity is a process that is difficult to be presented as an analytical model", Bedny and Karwowski [1]. Although the modelization of activity for analysis may be difficult, Ergonomics offers important strategies to work with. It allows one to understand which structure (subject, rules, work organization, objectives, goals, among others) are involved in the activity.

With this comprehension, it becomes easier to identify the SCA's, which also makes the understanding easier in both existing and analysis reference situations. From this detailed understanding of activity, it is possible to build not exactly future models of activity, but a flexible system capable of absorbing the variability of use situations. Within the concept of flexibility, it is possible to give the user a "margin in which to maneuver", with the users themselves providing solutions for the identified problems and/or improving the already existing systems. This deals, as a last resort, with "predicting the space of the possible forms of future activity", Daniellou [6].

The question is to realize that one cannot depend only on what the designer creates; today, one must separate the real context from the designing process. It is necessary to consider the activity as a whole, together with the relations that involve its components in an overlapping system of action. The contribution of ergonomics, in this sense, can be quite valuable, as it is focused on illustrating the relations that exist among the dimensions of a design which are habitually separate: definition of the product range, design of the product means, organizational definition, design programs, among others; this can occur through the recognition that what is separated in the design will be, in some way, joined in the end within the work activity [9]. "Therefore, we speak of the last resort in designing more than artifacts, designing activities, spaces for the permanent construction of experience" [18].

\section{1- Methodology-applied}

To take advantage of user experience, this research basically consisted of observing the users in an educational laboratory, by performing a simultaneous self-confrontation, given that the data survey was carried out during classes when both professors and students were together. Student work in the laboratory objectively involved two pieces of 
equipment, ELVIS - Educational Laboratory Virtual Instrumentation Suite (for more information on the ELVIS, visit www.ni.com) and a computer connected to ELVIS, which made it possible to simulate circuit boards and take measurements related to the practices proposed by the professor. ELVIS is the equipment that is most handled by the students and is the main object in use during most of the time.

Other actors and users were analyzed at distinct moments to contemplate other means through which to use the workbench. For this reason, the maintenance and janitorial crew from the laboratories were interviewed. With these users, the work had the objective of finding the main problems in interactions with the workbench from the point of view of their specific demands. Once collected, the data were organized in a table where the premises for the workbench were reported. The survey of the situation of the characteristic action allowed for the grouping of the data into categories according to the similarity of the situations. In the present article, table 1 presents some of the SCA's that were considered the most relevant in the conception process of the new workbench and describes the main problems identified by means of the analysis of the situations of characteristic actions.

Table 1 - Situations of characteristic actions in the measurement laboratories.

\begin{tabular}{|l|l|}
\hline SCA & Brief description \\
\hline Lecture classes, using the board & $\begin{array}{l}\text { The old workbench (Figure 2) blocks one from viewing the board. The seats cannot be } \\
\text { moved for the students to position themselves in front of the board and take notes at the same } \\
\text { time. }\end{array}$ \\
\hline $\begin{array}{l}\text { The attention the professor gives to the } \\
\text { working groups at each workbench }\end{array}$ & $\begin{array}{l}\text { The old workbenchs allow the professor to interact with only one pair at a time, a raised } \\
\text { portion on the front side of the workbench isolates the pairs from each other (blocks the } \\
\text { possible view of the equipment and interaction) }\end{array}$ \\
\hline The use of equipment on the workbenches & $\begin{array}{l}\text { The old workbench restricts the use of the equipment to two students, where one executes the } \\
\text { set-up while the other observes, as the equipment can only be approached from the front. The } \\
\text { same happens with the computer used in the classes. }\end{array}$ \\
\hline Interaction amongst students & $\begin{array}{l}\text { The interaction becomes difficult, given that the workbenchs align the working pairs in rows } \\
\text { (repeating the model of the traditional classrooms). It is common to see two or three pairs } \\
\text { discussing their doubts at one single workbench to later execute their own work at their own } \\
\text { workbench. In fact, this practice is encouraged by some professors to facilitate learning. }\end{array}$ \\
\hline
\end{tabular}

\section{4 - The Workbench - the old and the new}

The original idea was to design a new workbench (figure 01) which could act as a facilitator in the learning process, constructing an environment that is favorable to the exchange of experiences among the users of the electrical measurement laboratory, both amongst the students as well as with the professor. Substituting the old workbench became essential, as the data demonstrated that, despite the innumerous strategies developed by the users to overcome the difficulties, the work instrument - the workbench still presented a barrier to the main activities of both students and professors, as reported in table 1. 


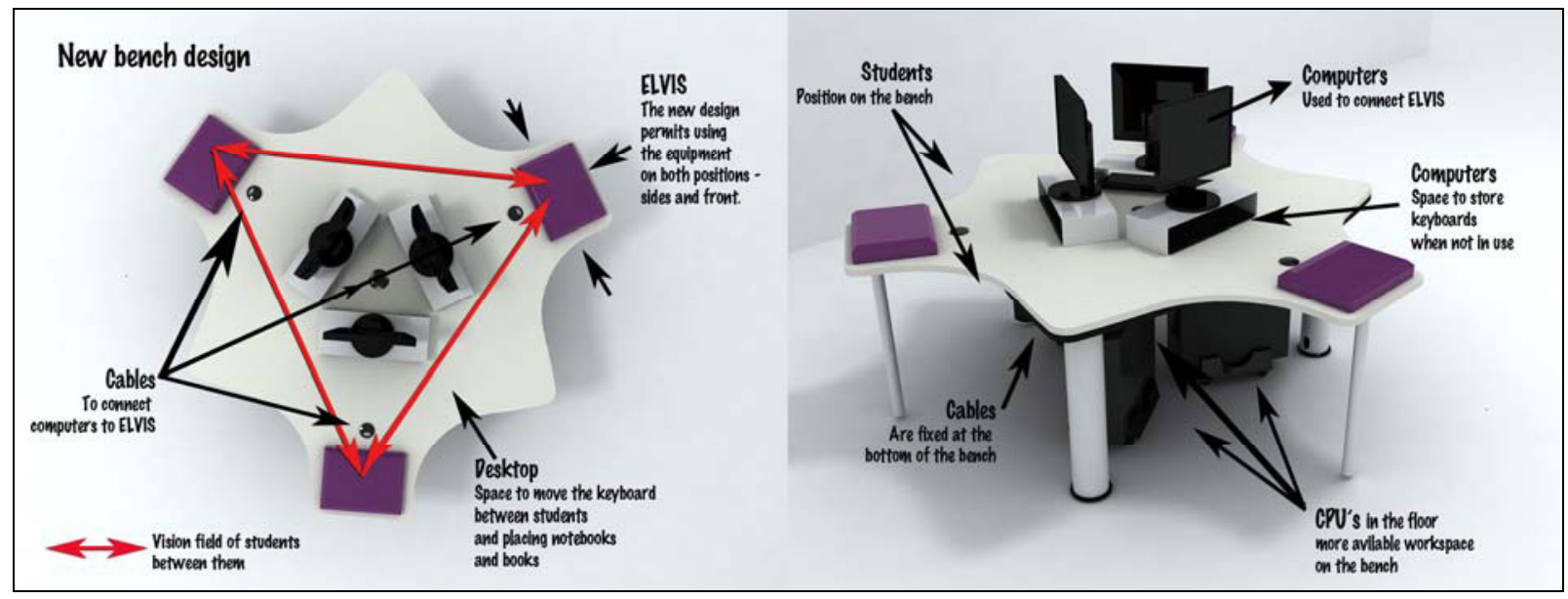

Figure 1- Project of new workbench

\section{1- The new workbench}

Once the analysis phase has been completed, as described above, and considering the identified utilization schemes, the project was begun under the following premise: build, in a consistent manner, an artifact that is capable of providing support to classes, both in lectures and in the attention provided by the professor to the student pairs, as well as construct an artifact that would act as a facilitator in the exchange of experience among students who are catalyzed in the steps pointed out by Clot [5] regarding the construction of a collective memory resulting from a social construction mediated by the artifact. In this manner, the main focus of this project was to incorporate, as much as possible, the utilization schemes developed by the user within the new artifact in such a way as to construct an artifact where the cognitive estrangement would be minimized. Once this estrangement has been reduced in the user as regards his/her interaction with the new artifact, the process of appropriation and instrumentalization is facilitated. In summary, the objective is to provide the user, in an organized and systematic manner, with that which their strategies and utilization schemes attempted to overcome when using the old workbench (figure 2). Table 2 presents the general characteristics of the proposed project meant to assume the condition of a new artifact of work in the educational laboratory.

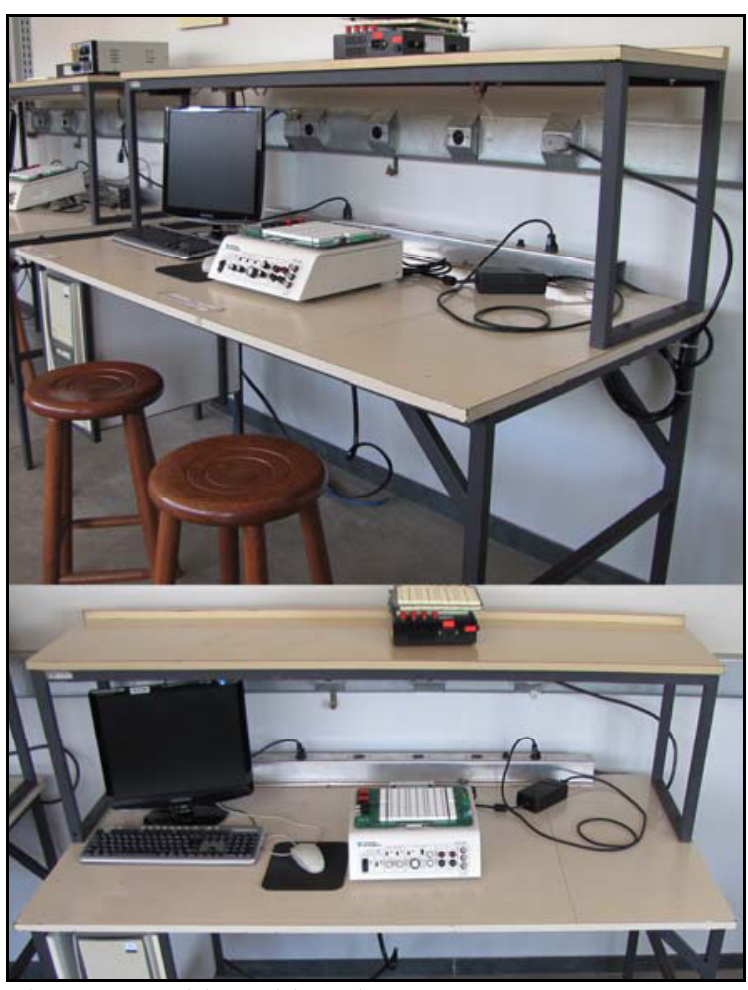

Figure 2 - Old workbench 
Table 2 - Characteristics of the design of the new workbench

\begin{tabular}{|c|c|}
\hline Activity & Characteristics of the workbench \\
\hline Lecture classes, using the board & $\begin{array}{l}\text { The workbench allows the students to move around the workstation, both to change } \\
\text { positions as well as to turn around, as the students use office swivel chairs. At a typical } \\
\text { height of a common table, the station allows the student to watch the explanation of the } \\
\text { professor and take notes, as it offers a space reserved for writing and eliminates the } \\
\text { blocking of one's view caused by the raised portion on the back portion of the old } \\
\text { workbench (Figure 1). }\end{array}$ \\
\hline $\begin{array}{l}\text { Attention given by the professor to working } \\
\text { groups at each workbench }\end{array}$ & $\begin{array}{l}\text { The workbenches allow the professor to intervene in three working groups at the same } \\
\text { time; as the great majority of student questions are in common, the professor can instruct } 3 \\
\text { pairs at once, thus optimizing his/her time, avoiding repetitions. This guarantees space to } \\
\text { dedicate to more uncommon questions that may arise and demand more time from the } \\
\text { professor. }\end{array}$ \\
\hline The use of workbench equipment & $\begin{array}{l}\text { The new workbench ensures the use of ELVIS by two students, in which both may } \\
\text { simultaneously execute the proposed set-up. This is made possible since the workbench } \\
\text { allows one to approach the equipment form the sides as well as from the front. The front } \\
\text { approach can be used by the professor or, in exceptional cases, by more than one student. } \\
\text { The same happens with the computer used for classes, the keyboard in this workbench can } \\
\text { be shared by the students in pairs without having to change positions, whereas before, they } \\
\text { were restricted to use by only one or the other; now the keyboard can simply be moved } \\
\text { across the workbench and placed in front of the student who will use it. }\end{array}$ \\
\hline Interaction amongst students & $\begin{array}{l}\text { The interaction is facilitated amongst the three pairs using the workbench. The fact is that } \\
\text { by accommodating three pairs, it thereby ensures that the pairs can see each other and can } \\
\text { observe how each pair is performing the work, in turn ensuring interaction, thus sharing } \\
\text { their doubts, strategies, and solutions. This represents more than mere interaction; in fact, it } \\
\text { gives incentive to collective work from the three pairs, but without the loss of the } \\
\text { individuality of each. }\end{array}$ \\
\hline
\end{tabular}

To construct the first prototype (figure 3) that, today, can be found in the test phase in the educational laboratory at UFMG.

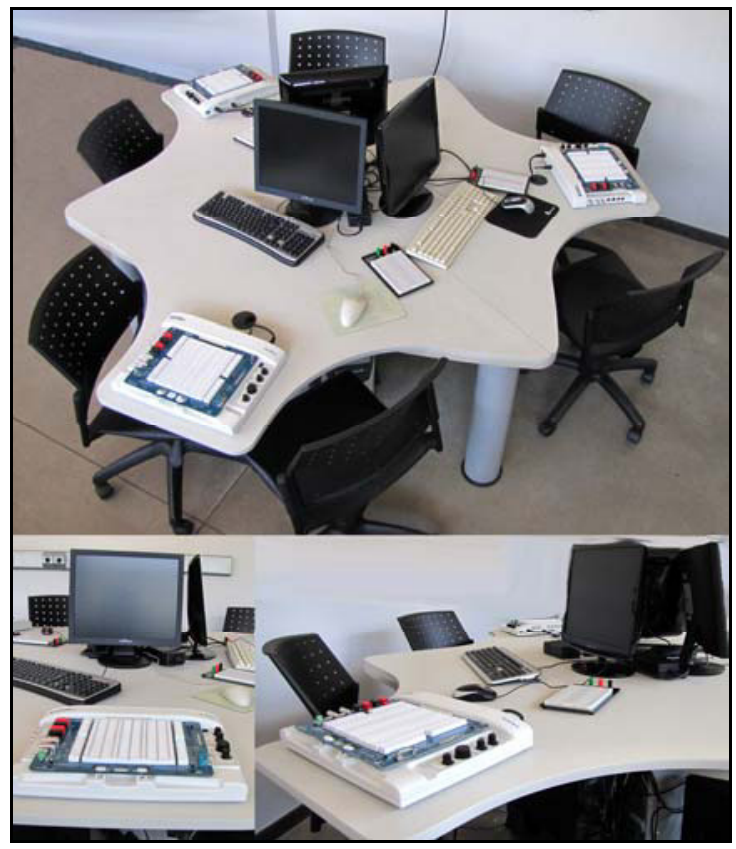

Figure 3 - First prototype of a new workbench
The UFMG research group set up a partnership with a furniture store in Belo Horizonte, Brazil. This industry is an important manufacturer of office and industrial furniture with important production technology resources. These resources allowed for the construction of a high-quality prototype in terms of finishing and constructive resources, which are nearly impossible to find at UFMG.

The next step of the project is to make the necessary adjustments identified during the initial tests of the first prototype in use. Having implemented the adjustments to the design, three workbenches will be built and a laboratory will be set up using only these. In this manner, in the laboratory specially constructed with these new artifacts, new tests will be performed to measure the level of learning of the students who will be working exclusively with the new workbenches. The obtained results will be compared to the measures of performance from the students who receive their hands-on classes in laboratories with the old workbenches.

In the present stage of the project, another partnership was set up with a research group from the UFMG School of Education. This group of researchers in educational methods and techniques is 
adapting the methodology so as to properly measure the performance levels in the two laboratories, one with the new workbenches and one with the old.

\section{5- Final considerations}

Observing, speaking with the users, applying questionnaires does not seem to be a novelty for design methods, yet one question remains: Why, despite the contact with the user and so many needs surveys, do the artifacts still present so many distortions and deficiencies concerning their use? What this work proposes here is to exhibit concrete results of a design process in which the recovery of the user experience appears as a key element to inform the needed design of the new artifacts, be this experience reflected in the utilization schemes, in the SCA's, and/or in the strategies developed by the user in overcoming their difficulties during their activities.

The fact is that, such elements are an integral part of the designed artifact and act as determining factors in the definition of the functional characteristics of the new workbench. The major expectation of future tests concerns students performance regarding their levels of learning. Nonetheless, during the tests with the first prototype, for the final adjustments, the indications of approval were already significant. Although this was not the original intention of the tests, as the present work focused on the finalization of the new workbench design, the students have already pointed out the advances in the quality of classes and the facilities that the workbench has brought in terms of use, which leads us to believe that the functional devices of the new workbench have in fact met the demands of the users. Our initial assessment is positive, considering the first reactions to the workbench design, which we believe is, at least in part, due to our proposal to reflect the users' experience within the final design.

\section{References}

[1] Bedny, G.; Karwowski, W. Systemic-structural theory of activity and design. In: _. A systemic-structural theory of activity - applications to human performance and work design London: Taylor \& Francis, 2007b. p. 51-114.

[2] Béguin, P. O ergonomista, ator de concepção. In: Falzon, Pierre (Ed.). Ergonomia. São Paulo: Ed. Edgard Blücher, 2007. p. $318-330$
[3] Béguin, P.; Duarte, F. A inovação: entre o trabalho dos projetistas e o trabalho dos operadores. Laboreal, Porto, Portugal, 2008 v. 4, n. 2, p. 10-14.

4] Caverni, J.P. "La verbalisation comme source d'observables pour l'étude du fonctionnement cognitif". In: Caverni, J.P.; Bastien, C.; Mendelsohn; Tiberghien, G. (eds). Psychologie cognitive. Grenoble, PUG, 1991 (2e ed.).

[5] Clot, Y. Trabalho e poder de agir. Belo Horizonte: Fabrefactum Editora, 2010

[6] Daniellou, F. A ergonomia na condução de projetos de concepção de sistemas de trabalho. In: Falzon, Pierre (Ed.). Ergonomia. São Paulo: Ed. Edgard Blücher, 2007. p. 303316

[7] Daniellou, F. et al. "Ficção e realidade do trabalho operário". Rev. Bras. de Saúde Ocupacional, 1989, v.65, n.17, p. 7-13.

[8] Daniellou, F. Le statut de al pratique et des connaissances dans l'intervention ergonomique de conception. Toulouse: Université de Toulouse, 1992.

[9] Daniellou, F. Questões epistemológicas levantadas pela ergonomia de projeto. In: ___ A ergonomia em busca de seus princípios - debates epistemológicos. São Paulo: Ed. Edgard Blücher, 2004. p. 181-198.

[10]Daniellou, F.; Béguin, P. Metodologia da ação ergonômica: abordagens do trabalho real. In: Falzon, Pierre (Ed.). Ergonomia. São Paulo: Ed. Edgard Blücher, 2007. p. 281300

[11]Engeströn, Y. Activity theory as framework for analyzing and redesigning work. Ergonomics, 2000 v. 43, n. 7, p. $960-$ 974.

[12]Folcher, V.; Rabardel, P. Homens, artefatos, atividades: perspectiva instrumental. In: Falzon, Pierre (Ed.). Ergonomia São Paulo: Ed. Edgard Blücher, 2007. p. 59-65.

[13] Guérin et al. Comprendre le travail pour le transformer. Paris, Anact, 1991.

[14]Léontiev, A. N. Activity, consciousness and personality. New Jersey: Englewood Clifts Prentice Hall, 1978.

[15]Lima. F.P.A. \& Silva, C. A. “A objetivação do saber prático em sistemas especialistas: das regras formais às situações de ação". In: Duarte, F. Ergonomia na indústria de processos contínuos. Rio de Janeiro, 1998.

[16] Rabardel, P.; Waern, Y. From artifact to instrument. Interacting with computers. v. 15. Amsterdam: Elsevier, 2003. p. 641-645.

[17] Rabardel, P. Les hommes et les technologies. Paris, Armando Colin, 1995.

[18]Resende, A. E.; Mautner, Y. M. M.; Ornstein, S. W. Projeto como reflexo da experiência de uso: o caso de um centro de controle operacional. Encontro Nacional do Ambiente Construído - ENTAC, Canela, 2010. p. 185-194.

[19] Theureau, J. Le cours d'action: analyse sémio-logique. Berne, Peter Lang, 1992.

[20] Vermersch, P. L'entretien d'explicitation. Paris, ESF Éditeur, 1994.

[21] Vygotsky, L. S. Selected psychological research. Moscow: Academy of Psychological Science, 1956.

[22]Wisner, A. "La méthodologie en ergonomie: d'hier à aujourd'hui". Actes du XXVIe Congrès de la SELF, Montréal, 1990. 